\title{
Integrated Small Dense Low-density Lipoprotein Profile in Cardiovascular Disease and Cancer: A Longitudinal Study
}

\author{
MARIA NOTARNICOLA ${ }^{1}$, VALENTINA DE NUNZIO ${ }^{1}$, VALERIA TUTINO ${ }^{1}$, NICOLA VERONESE ${ }^{2}$, \\ VITO GUERRA ${ }^{3}$, ALBERTO R. OSELLA ${ }^{4}$, MARIA GABRIELLA CARUSO ${ }^{2}$ and MICOL GROUP ${ }^{\S}$ \\ ${ }^{1}$ Laboratory of Nutritional Biochemistry, \\ National Institute of Gastroenterology-Research Hospital, Castellana Grotte, Italy; \\ ${ }^{2}$ Ambulatory of Clinical Nutrition, \\ National Institute of Gastroenterology-Research Hospital, Castellana Grotte, Italy; \\ ${ }^{3}$ Scientific Direction, National Institute of Gastroenterology-Research Hospital, Castellana Grotte, Italy; \\ ${ }^{4}$ Laboratory of Epidemiology and Biostatistics, \\ National Institute of Gastroenterology-Research Hospital, Castellana Grotte, Italy
}

\begin{abstract}
Background/Aim: Low-density lipoproteins ( $L D L)$ are a heterogeneous class of particles that differ in size and density from each other. Small dense $L D L$ (sdLDL) particles are considered more atherogenic than larger particles. The aim of the study was to evaluate serum levels of sdLDL in patients who died from cardiovascular diseases $(C V D)$ or cancer in a cohort of patients followed up in the De Bellis Research Hospital for 20 years. Patients and Methods: A total of 75 participants who died of cancer and 87 who died of CVD were enrolled and they were matched for age and sex with 135 healthy controls, i.e. without CVD or cancer and are still alive. Results: Patients who died from cancer had the highest value of LDL IV subfraction $(0.25 \pm 1.16)$,

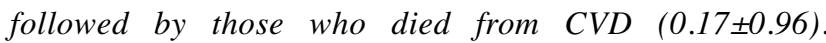
Conclusion: The integrated profile of sdLDL between CVD and cancer suggests that therapeutic modulation of sdLDL may be associated with a risk reduction for these diseases.
\end{abstract}

\$MICOL GROUP: De Michele Giampiero, Mastrosimini Anna, Iacovazzi Palma, Laboratory of Clinic Pathology, IRCCS Saverio de Bellis, Castellana Grotte, Bari, Italy; Chiloiro Marisa, Noviello Marisa, Unit of Radiology, IRCCS Saverio de Bellis, Castellana Grotte, Bari, Italy; Burattini Osvaldo, Pugliese Vittorio, Bonfiglio Caterina, Cisternino Annamaria, Laboratory of Biostatistic and Epidemiology, IRCCS Saverio de Bellis, Castellana Grotte, Bari, Italy; D'Attoma Benedetta, Laboratory of Biochemistry, IRCCS Saverio de Bellis, Castellana Grotte, Bari, Italy.

Correspondence to: Maria Gabriella Caruso, Via Turi 2770013 Castellana Grotte, Bari, Italy. Tel: +39 0804994669, e-mail: gabriella.caruso@irccsdebellis.it

Key Words: sdLDL, cardiovascular disease, cancer.
It is well demonstrated that hyperlipidemia is a potential risk factor for various metabolic diseases such as cardiovascular and malignant disorders (1-3). High low- density lipoprotein (LDL) levels seem to be associated with cardiovascular events and progression of coronary heart disease (4), as well as with the predisposition to develop a neoplastic disease (5).

Elevated total levels of cholesterol and LDL have been identified as potent risk factors in cancer $(6,7)$. In this context, excess adipose tissue, especially visceral adipose tissue (VAT) is often associated with an uncontrollable cell growth influencing carcinogenic processes (8). Obesity, often related to elevated triglycerides and LDL serum levels, is a risk factor for gastrointestinal neoplasms (5). Obese patients generally present a chronic, low-grade inflammation associated with an increase of insulin levels in blood, influencing cell growth and carcinogenesis $(5,9)$.

Several studies have demonstrated that both quantity of LDL and quality (particularly small, dense LDL) may increase cardiovascular risk (10-12). LDL are a heterogeneous class of particles composed of subfractions that differ in size and density from each other. LDL subfractions vary also in their risk profile, since small dense LDL (sdLDL) particles are more atherogenic than larger particles and are considered an emerging cardiovascular risk factor, independent of traditional risk factors such as total cholesterol levels (13). sdLDL have reduced binding capacities to LDL-receptors showing a stronger affinity to extracellular matrix and a major tendency to oxidative modification (14). The presence of sdLDL particles is associated with two- to three-fold increase in the risk of coronary heart disease (15).

Accumulating evidence suggests that cardiovascular diseases (CVD), diabetes and cancer share common pathogenetic factors (16). Dyslipidemia has been shown to contribute to the occurrence of malignant diseases, probably due to the onset of 
Table I. Baseline characteristics of people having incident cancer (IC), cardiovascular disease (CVD) and healthy controls (CTR).

\begin{tabular}{|c|c|c|c|c|c|}
\hline & \multirow[b]{2}{*}{$\mathrm{IC}(\mathrm{n}=75)$} & \multirow[b]{2}{*}{ CVD $(n=87)$} & \multirow[b]{2}{*}{ CTR $(n=135)$} & \multicolumn{2}{|c|}{ Comparison $p$-Value } \\
\hline & & & & (CTR vs. IC) & (CTR vs. CVD) \\
\hline Age & $70 \pm 8.4$ & $75 \pm 7.8$ & $72 \pm 8.4$ & & \\
\hline \multicolumn{6}{|l|}{ Gender } \\
\hline $\mathrm{F}$ & 27 & 53 & 56 & & \\
\hline M & 48 & 34 & 79 & & \\
\hline Total Cholesterol (mg/dl) & $185.1 \pm 39.58$ & $187.7 \pm 36.71$ & $194.7 \pm 33.94$ & 0.162 & 0.348 \\
\hline $\mathrm{HDL}(\mathrm{mg} / \mathrm{dl})$ & $50.35 \pm 10.21$ & $48.79 \pm 10.66$ & $50.40 \pm 11.69$ & 0.958 & 0.371 \\
\hline Total LDL (mg/dl) & $107.7 \pm 29.11$ & $110.7 \pm 31.54$ & $112.3 \pm 25.37$ & 0.498 & 0.911 \\
\hline LDL I (mg/dl) & $36.55 \pm 11.7$ & $35.34 \pm 12.03$ & $38.80 \pm 9.95$ & 0.335 & 0.063 \\
\hline LDL II (mg/dl) & $16.7 \pm 10.59$ & $20.75 \pm 13.68$ & $19.87 \pm 10.72$ & 0.106 & 0.849 \\
\hline LDL III (mg/dl) & $2.10 \pm 4.17$ & $2.43 \pm 4.5$ & $1.88 \pm 2.54$ & 0.898 & 0.508 \\
\hline LDL IV (mg/dl) & $0.25 \pm 1.16$ & $0.17 \pm 0.96$ & $0.007 \pm 0.08$ & 0.028 & 0.034 \\
\hline
\end{tabular}

F, female; M, male; HDL, high-density lipoprotein; LDL, low-density lipoprotein.

inflammatory processes and insulin resistance (17). Previously, we have demonstrated that elevated serum lipid levels may facilitate the development of distant metastasis in colorectal cancer (CRC) patients (7). Recently, we also observed high levels of sdLDL particles in serum of CRC patients with synchronous metastasis compared to ones without metastasis (18). This altered pattern was also associated with higher serum levels of oxidized and glycated low density lipoprotein (oxLDL and gly-LDL) in the same patients.

The relationship between the malignant phenotype and hyperlipidemia may be explained by an increased demand for cholesterol from neoplastic cells, resulting also in an increased endogenous cholesterol synthesis. High LDL levels have been reported to inhibit T-cell proliferation and to suppress the immune system facilitating tumor invasion and survival of colorectal cancer cells in lymph nodes and distant metastases (19).

Taken together, all these data suggest that traditional approaches to the study of lipids likely addressed only a small fraction of lipid complexity. Then, if it is true that much is known about the role of sdLDL in cardiovascular risk assessment, there is no evidence on their clinical significance in cancer. For this purpose, here, we measured serum LDL particle size in patients died from CVD or cancer in a cohort of patients followed-up in the De Bellis Research Hospital for 20 years. A control group of subjects died from natural causes was also enclosed in the study.

\section{Patients and Methods}

Patients. Participants were enrolled from the project MICOL (Multicentric Italian Cholelithiasis). MICOL, a population-based study started in 1985, consisted of a systematic random sample of the Castellana Grotte population aged 30-69 years that was followed up and recalled for the third time between 2005 and
2006. For the aims of our research, we used the serum samples collected at the third assessment made in 2005. The population enrolled in 2005 (third assessment) consisted of 1,708 subjects (among 1,942 initially contacted or re-called), 950 males and 758 females. The MICOL study was approved by the Institutional Review Board (Ethics Committee) of the De Bellis Research Hospital and written informed consent was obtained from each participant.

Measurements. The survey visit consisted of the administration of a standardized questionnaire, including a validated semi-quantitative food frequency questionnaire, anthropometric measurements, a blood sample for biochemical tests, and an ultrasonographic examination. Blood sampling was performed in the morning after overnight fasting and biochemical measurements were recorded using standardized methods. For the purposes of this research, we included: (a) a smoking habit categorized as previous/current $v s$. never; (b) body mass index (BMI) and waist circumference, recorded by a trained physician or nurse using standardized methods; (c) blood pressure (systolic and diastolic), recorded once at the right arm; (d) daily energy and alcohol intake; (e) selfreported history of diabetes, gastric ulcer, previous cancer (more than five years before the interview), and acute myocardial infarction. Aliquots of blood samples, collected in tubes containing Ethylen-diamine-tetraacetic Acid (EDTA-K2) anticoagulant, were centrifuged at $2,000 \times g$ for $10 \mathrm{~min}$ at $4^{\circ} \mathrm{C}$ and stored in biobank at $-80^{\circ} \mathrm{C}$ until they were used.

Definition of cases and controls. In MICOL III, mortality was adjudicated through death certificates, manually revised by a trained researcher. The examination of the death certificates was performed until 31 December 2017. Cardiovascular death was assigned based on ICD (International Classification of Diseases) 10 codes from I00 to 199 and cancer-related death was associated with codes from $\mathrm{C} 00$ to $\mathrm{C} 97$. Using this system, we included 75 participants who died from cancer during the follow-up period and 87 who died from CVD. These cases were matched for age and sex with persons without cancer and/or CVD and still alive at $31 / 12 / 2017$. 


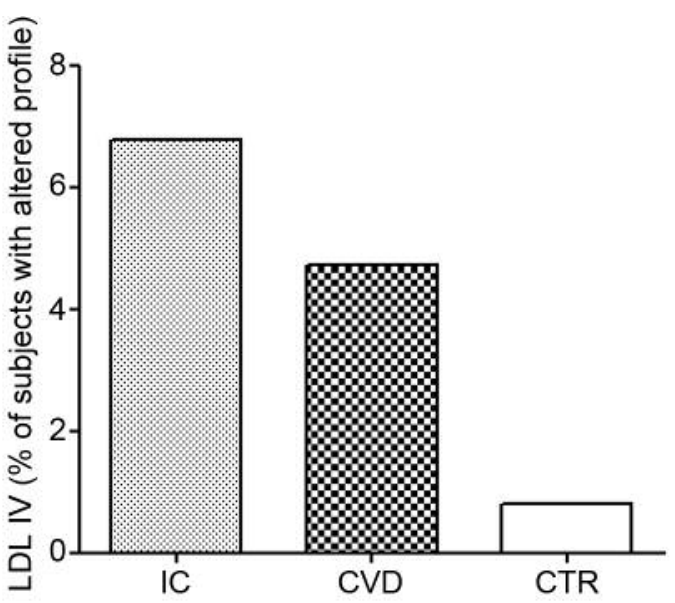

Figure 1. Prevalence of $L D L I V$ in individuals having incident cancer (IC), cardiovascular diseases (CVD) and healthy controls (CTR).

Small dense LDL analysis. sdLDL were assayed using the Lipoprint LDL System (Quantimetrix, Redondo Beach, CA, USA). Each serum sample was applied on high resolution polyacrylamide gel tube in order to separate LDL fractions and subfractions by electrophoresis. The resolved lipoprotein bands were scanned and analyzed.

Statistical analysis. For continuous variables, normal distributions were tested using the Kolmogorov-Smirnov test. The data are reported as means and standard deviations (SD) for continuous measures, and percentages for all categorical variables by cases and controls. For continuous variables, differences between the means of the covariates by group were calculated using an Analysis of Variance (ANOVA); chi-square test was applied for categorical variables. Levene's test was used to test the homoscedasticity of variances and, if its assumption was violated, Welch's ANOVA was used. Post-hoc analyses were applied to compare data. All the $p$ values were reported taking the healthy controls as a reference.

The Bonferroni correction was not used since it has been criticized for reasons such as high risk for type II errors, and the lack of consensus on how many comparisons warrants this correction (20).

All analyses were performed using the SPSS 17.0 for Windows (SPSS Inc., Chicago, IL, USA). All statistical tests were two-tailed and statistical significance was assumed for a $p$-value $<0.05$, without using the Bonferroni's correction as mentioned before.

\section{Results}

The population enrolled in 2005 (third assessment of the MICOL III) consisted of 1,708 subjects (among 1,942 initially contacted or re-called), 950 males and 758 females. Among them, we included 75 participants who died from cancer during follow-up period and 87 who died from CVD. These participants were matched for age and sex with 135 healthy controls, i.e. without CVD or cancer and still alive.
Table I shows the main characteristics of the participants included. No significant differences emerged for total serum cholesterol, HDL or total LDL. Moreover, no significant differences emerged for LDL subfractions, except for LDL IV. For the latter subfraction, in fact, we found that people who died from cancer had the highest value of LDL IV $(0.25 \pm 1.16)$, followed by those with CVD $(0.17 \pm 0.96)$ and by healthy controls $(0.007 \pm 0.08$ ) ( $p$ for comparison between cancer and healthy controls was 0.028 and between CVD and controls was 0.034) (Table I). We further investigated the prevalence of any LDL IV subfraction, categorized as presence or not of this subfraction (Figure 1). Again, we found that only $1 / 135(0.7 \%)$ among controls had this abnormal component, while 4/87 (4.7\%) patients with CVD and $5 / 75(6.7 \%)$ patients with cancer.

\section{Discussion}

The strength of the present study consists in evaluating incident cases of CVD and cancer in a cohort of subjects, already followed-up in our Institute for 20 years. This is a longitudinal study that allowed evaluation of serum LDL subfractions in order to characterize the risk for metabolic diseases as CVD and cancer. The pathological profile of LDL was associated with death from CVD or cancer, suggesting that the qualitative analysis of LDL particles has a clinical significance, overall in the risk evaluation for these pathological conditions. Compared to control subjects, higher levels of atherogenic LDL subfraction (LDL IV) were detected in the serum of CVD and cancer cases.

Common pathways in the pathogenesis of CVD and cancer, specifically CRC, have been demonstrated in different studies (21-23). Both atherogenesis and carcinogenesis, known as chronic inflammatory states, start with alterations occurring in lipid metabolism, obesity and diabetes mellitus $(21,24)$. The conditions leading to CVD, as well as the tumor microenvironment contain inflammatory factors such as tumor necrosis factor-alpha and interleukin6 , capable of inducing chronic inflammation (25). In this context, LDL particles play also a central role, being key molecules in both the initiation and progression of tissue inflammation through platelets activation and vascular endothelial cells injury (26). In particular, the smaller LDL fractions show greater trans endothelial transport and an increased oxidative susceptibility (27). The association between sdLDL and vascular disease suggests that carotid atherosclerosis regression or progression is linked to LDL size (10).

In light of these considerations, apart from the role of sdLDL in stratification of risk and prevention, this LDL subclass is, certainly, significant with respect to treatment modality and progression of the disease. The integrated profile of sdLDL in CVD and cancer detected in our study 
suggests that therapeutic modulation of sdLDL may be associated with a reduction of CVD and cancer risk.

However, the significance of sdLDL analysis needs to be supported by a predictive study on a larger population sample, so that screening for the presence of sdLDL may identify subjects with a higher risk for developing metabolic diseases which share common risk factors and biological basis.

\section{Conflicts of Interest}

The Authors declare no conflicts of interest regarding this study.

\section{Authors' Contributions}

Conceptualization: MN, MGC; Data curation: VDN, VT, VG, NV; Methodology: VDN, VT, MICOL GROUP; Supervision: NV, MGC, ARO; Writing: MN, MGC.

\section{Acknowledgements}

This work was supported by RC 2019-2021, project CC025 (DDG n. 748/2018).

\section{References}

1 Nordestgaard BG and Varbo A: Triglycerides and cardiovascular disease. Lancet 384(9943): 626-635, 2014. PMID: 25131982. DOI: $10.1016 / \mathrm{S} 0140-6736(14) 61177-6$

2 Silvente-Poirot S and Poirot M: Cancer. Cholesterol and cancer, in the balance. Science 343(6178): 1445-1446, 2014. PMID: 24675946. DOI: $10.1126 /$ science. 1252787

3 Ghahremanfard F, Mirmohammadkhani M, Shahnazari B, Gholami $G$ and Mehdizadeh J: The valuable role of measuring serum lipid profile in cancer progression. Oman Med J 30(5): 353-357, 2015. PMID: 4576393. DOI: 10.5001/omj.2015.71

4 Iyen B, Qureshi N, Kai J, Akyea RK, Leonardi-Bee J, Roderick P, Humphries SE and Weng S: Risk of cardiovascular disease outcomes in primary care subjects with familial hypercholesterolaemia: A cohort study. Atherosclerosis 287: 8-15, 2019. PMID: 31181417. DOI: 10.1016/j.atherosclerosis.2019.05.017

5 Tarasiuk A, Mosinska P and Fichna J: The mechanisms linking obesity to colon cancer: An overview. Obes Res Clin Pract 12(3): 251-259, 2018. PMID: 29428365. DOI: 10.1016/j.orcp. 2018.01.005

6 Dessi S, Batetta B, Pulisci D, Spano O, Anchisi C, Tessitore L, Costelli P, Baccino FM, Aroasio E and Pani P: Cholesterol content in tumor tissues is inversely associated with high-density lipoprotein cholesterol in serum in patients with gastrointestinal cancer. Cancer 73(2): 253-258, 1994. PMID: 8293385. DOI: 10.1002/10970142(19940115)73:2<253::aid-cncr2820730204>3.0.co;2-f

7 Notarnicola M, Altomare DF, Correale M, Ruggieri E, D'Attoma B, Mastrosimini A, Guerra V and Caruso MG: Serum lipid profile in colorectal cancer patients with and without synchronous distant metastases. Oncology 68(4-6): 371-374, 2005. PMID: 16020965. DOI: $10.1159 / 000086977$

8 Divella R, De Luca R, Abbate I, Naglieri E and Daniele A: Obesity and cancer: The role of adipose tissue and adipo- cytokines-induced chronic inflammation. J Cancer 7(15): 23462359, 2016. PMID: 5166547. DOI: 10.7150/jca.16884

9 Calle EE and Kaaks R: Overweight, obesity and cancer: Epidemiological evidence and proposed mechanisms. Nat Rev Cancer 4(8): 579-591, 2004. PMID: 15286738. DOI: 10.1038/ nrc1408

10 Rizzo $\mathrm{M}$ and Berneis $\mathrm{K}$ : Low-density lipoprotein size and cardiovascular risk assessment. QJM 99(1): 1-14, 2006. PMID: 16371404. DOI: 10.1093/qjmed/hci154

11 Krychtiuk KA, Kastl SP, Pfaffenberger S, Lenz M, Hofbauer SL, Wonnerth A, Koller L, Katsaros KM, Pongratz T, Goliasch G, Niessner A, Gaspar L, Huber K, Maurer G, Dostal E, Wojta J, Oravec S and Speidl WS: Association of small dense ldl serum levels and circulating monocyte subsets in stable coronary artery disease. PLoS One 10(4): e0123367, 2015. PMID: 4388574. DOI: 10.1371/journal.pone.0123367

12 Gentile M, Iannuzzo G, Mattiello A, Rubba F, Panico S and Rubba P: Association between body shape index and small dense ldl particles in a cohort of mediterranean women: Findings from progetto atena. J Clin Biochem Nutr 61(2): 130-134, 2017. PMID: 5612817. DOI: $10.3164 /$ jcbn.17-13

13 Malhotra J, Tonorezos ES, Rozenberg M, Vega GL, Sklar CA, Chou J, Moskowitz CS, Eshelman-Kent DA, Janiszewski P, Ross $\mathrm{R}$ and Oeffinger KC: Atherogenic low density lipoprotein phenotype in long-term survivors of childhood acute lymphoblastic leukemia. J Lipid Res 53(12): 2747-2754, 2012. PMID: 3494249. DOI: 10.1194/jlr.P029785

14 Stevanovic M, Vekic J, Bogavac-Stanojevic N, Janac J, Stjepanovic Z, Zeljkovic D, Trifunovic B, SpasojevicKalimanovska V and Zeljkovic A: Significance of ldl and hdl subclasses characterization in the assessment of risk for colorectal cancer development. Biochem Med (Zagreb) 28(3): 030703, 2018. PMID: 6214700. DOI: 10.11613/BM.2018. 030713

15 Lamarche B, Lemieux I and Despres JP: The small, dense ldl phenotype and the risk of coronary heart disease: Epidemiology, patho-physiology and therapeutic aspects. Diabetes Metab 25(3): 199-211, 1999. PMID: 10499189.

16 Xie C, Wang ZC, Liu XF and Yang MS: The common biological basis for common complex diseases: Evidence from lipoprotein lipase gene. Eur J Hum Genet 18(1): 3-7, 2010. PMID: 2987160. DOI: 10.1038/ejhg.2009.134

17 Agnoli C, Grioni S, Sieri S, Sacerdote C, Vineis P, Tumino R, Giurdanella MC, Pala V, Mattiello A, Chiodini P, Iacoviello L, De Curtis A, Cattaneo L, van Duijnhoven FJ, Panico S and Krogh V: Colorectal cancer risk and dyslipidemia: A case-cohort study nested in an italian multicentre cohort. Cancer Epidemiol 38(2): 144-151, 2014. PMID: 24636241. DOI: 10.1016/j.canep. 2014.02.002

18 Notarnicola M, Caruso MG, Tutino V, De Nunzio V, Gigante I, De Leonardis G, Veronese N, Rotolo O, Reddavide R, Stasi E, Miraglia C, Nouvenne A, Meschi T, De' Angelis GL, Di Mario $\mathrm{F}$ and Leandro G: Nutrition and lipidomic profile in colorectal cancers. Acta Biomed 89(9-S): 87-96, 2018. PMID: 6502197. DOI: $10.23750 / \mathrm{abm} . v 89 \mathrm{i9}-\mathrm{S} .7955$

19 Mehta N, Hordines J, Sykes D, Doerr RJ and Cohen SA: Low density lipoproteins and lovastatin modulate the organ-specific transendothelial migration of primary and metastatic human colon adenocarcinoma cell lines in vitro. Clin Exp Metastasis 16(7): 587-594, 1998. PMID: 9932605. 
20 Perneger TV: What's wrong with bonferroni adjustments. BMJ 316(7139): 1236-1238, 1998. PMID: 1112991. DOI: 10.1136/ bmj.316.7139.1236

21 Chan AO, Jim MH, Lam KF, Morris JS, Siu DC, Tong T, Ng FH, Wong SY, Hui WM, Chan CK, Lai KC, Cheung TK, Chan P, Wong G, Yuen MF, Lau YK, Lee S, Szeto ML, Wong BC and Lam SK: Prevalence of colorectal neoplasm among patients with newly diagnosed coronary artery disease. JAMA 298(12): 14121419, 2007. PMID: 17895457. DOI: 10.1001/jama.298.12.1412

22 Yang MH, Cho J, Choi YH, Son HJ, Rhee JC and Sung J: The association between coronary artery calcification and colorectal adenoma. Hepatogastroenterology 60(123): 538-542, 2013. PMID: 23108081. DOI: 10.5754/hge12709

23 Basyigit S, Ozkan S, Uzman M, Ertugrul DT, Kefeli A, Aktas B, Yeniova AO, Asilturk Z, Nazligul Y, Simsek H, Simsek G, Ayturk $M$ and Yavuz B: Should screening for colorectal neoplasm be recommended in patients at high risk for coronary heart disease: A cross-sectional study. Medicine (Baltimore) 94(20): e793, 2015. PMID: 4602862. DOI: 10.1097/MD.0000000000000793

24 Mantovani A, Allavena P, Sica A and Balkwill F: Cancer-related inflammation. Nature 454(7203): 436-444, 2008. PMID: 18650914. DOI: $10.1038 /$ nature 07205
25 Shoelson SE, Lee J and Goldfine AB: Inflammation and insulin resistance. J Clin Invest 116(7): 1793-1801, 2006. PMID: 1483173. DOI: $10.1172 /$ JCI29069

26 Bjornheden $\mathrm{T}$, Babyi A, Bondjers $\mathrm{G}$ and Wiklund $\mathrm{O}$ : Accumulation of lipoprotein fractions and subfractions in the arterial wall, determined in an in vitro perfusion system. Atherosclerosis 123(1-2): 43-56, 1996. PMID: 8782836. DOI: 10.1016/0021-9150(95)05770-6

27 Tribble DL, Rizzo M, Chait A, Lewis DM, Blanche PJ and Krauss RM: Enhanced oxidative susceptibility and reduced antioxidant content of metabolic precursors of small, dense lowdensity lipoproteins. Am J Med 110(2): 103-110, 2001. PMID: 11165551. DOI: 10.1016/s0002-9343(00)00700-2

Received September 19, 2019

Revised September 30, 2019 Accepted October 1, 2019 